\title{
Colorectal Disease and Surgery: Diagnosis and Treatment
}

\section{Keun-Yeong Jeong}

Gachon Institute of Pharmaceutical Sciences, Gachon University, Incheon, 406-840, Republic of Korea

Over the last several decades, the remarkable advances were given in clinical and preclinical science. We have been fortunate to witness the integration of multiple areas of discovery in science and medicine to push the envelope for the diagnosis and treatment of disorders that can affect the body, especially in the colon disease [1]. In developed countries, life expectancy continues to increase. With the increasing growth and lifetime of the world's people, it is expected that the incidence of a number of diseases also will continue to grow [2].

As a result, multiple novel therapeutics are currently being advanced to treat many disorders that currently have limited medicines. Nutrition supplementation has reported that dietary calcium plays a key role in the chemoprevention of colon carcinogenesis [3]. In terms of cell therapy, stem cell applications have quickly advanced and are being considered for colon disease including cancer $[4,5]$. Unique treatment options for treatment of colorectal cancer are heated intraperitoneal chemotherapy [6]. Heated intraperitoneal chemotherapy is performed at the end of surgery to remove abdominal tumors. Once tumors have been removed, the surgeon continuously circulates a heated, sterile chemotherapy solution throughout the peritoneal cavity. Actually, the optimal option for cure of colorectal cancer is drug therapies that attack the abnormal signaling processes that cause colorectal cancer cells to grow, innovative therapies that boost the immune response, antibodies to attack cancer, and drugs to stop blood flow to tumors, such as bevacizumab [7]. Although these beneficial is intimately connected through cellular pathways that can significantly affect clinical outcome in patients. It is clear that cellular and genetic targets can easily impact many disease entities. The translation of these pathways into relevant clinical treatments can yield reward for colorectal cancer.

Colorectal Disease and Surgery is a special issue of International Journal of Gastroenterology Disorders and Therapy, publishing original research in any discipline relating to colorectal diseases. Colorectal Disease and Surgery will focus upon the translation of cellular, molecular, and genetic pathways into clinical and preclinical strategies for multiple scientific disciplines that can impact a broad spectrum of colorectal disease. These disorders can involve all aspects of translational research and medicine to include anal fissures, cancer of the small intestine, colitis, colon cancer, diverticulitis, fecal incontinence, fistulae, rectal cancer, rectal prolapse, hemorrhoids, and hereditary polyposis.

Colorectal disease and Surgery will provide a platform in scientific and medical literature to serve as an international discussion for the scientific and clinical communities worldwide to translate basic and clinical research studies into good therapies as well as report upon prognostics, novel therapeutic strategies, and biomarker development. Colorectal disease and Surgery will offer multiple venues to present authors' thoughts and investigations as original research, review, commentary, letter to editor, hypothesis, short Commentary etc.

Finally, colorectal disease and Surgery will encourage a constructive evaluation of all submitted articles. Papers will be processed in the timely fashion so that all authors can follow the progress of the papers during the evaluation and publication phases. Colorectal disease

\section{Publication History:}

Received: October 28, 2015

Accepted: December 05, 2015

Published: December 08, 2015

\section{Keywords:}

Colorectal disease, Carcinogenesis, Preclinical scienc

and Surgery will serve as an opportunity for the greatest degree of scholarship in the research and clinical communities international to translate innovative "bench to bedside" advances into successful scientific strategies.

\section{References}

1. Ciombor KK, Wu C, Goldberg RM (2015) Recent therapeutic advances in the treatment of colorectal cancer. Annual review of medicine 66: 83-95.

2. Bouvier AM, Launoy G (2015) [Epidemiology of colorectal cancer]. La Revue du praticien 65: 767-773.

3. Kallay E, Wrba F, Cross HS (2003) Dietary calcium and colon cancer prevention. Forum of nutrition 56: 188-190.

4. Haga E, Endo Y, Haruta M, Koba C, Matsumura K, et al. (2014) Therapy of peritoneally disseminated colon cancer by TAP-deficient embryonic stem cell-derived macrophages in allogeneic recipients. Journal of immunology 193: 2024-2033.

5. Knoop K, Schwenk N, Schmohl K, Muller A, Zach C, et al. (2015) Mesenchymal stem cell-mediated, tumor stroma-targeted radioiodine therapy of metastatic colon cancer using the sodium iodide symporter as theranostic gene. Journal of nuclear medicine: official publication, Society of Nuclear Medicine 56: 600-606.

6. Maillet M, Glehen O, Lambert J, Goere D, Pocard M, et al. (2015) Early Postoperative Chemotherapy After Complete Cytoreduction and Hyperthermic Intraperitoneal Chemotherapy for Isolated Peritoneal Carcinomatosis of Colon Cancer: A Multicenter Study. Ann Surg Oncol.

7. Zhang SD, McCrudden CM, Meng C, Lin Y, Kwok HF (2015) The significance of combining VEGFA, FLT1, and KDR expressions in colon cancer patient prognosis and predicting response to bevacizumab. Onco Targets and Therapy 8: 835-843.

"Corresponding Author: Dr. Keun-Yeong Jeong, Gachon Institute of Pharmaceutical Science, Gachon University, Incheon, Republic of Korea; E-mail: alvirus@naver.com

Citation: Jeong KY (2015) Colorectal Disease and Surgery: Diagnosis and Treatment. Int $\mathrm{J}$ Gastroenterol Disord Ther 2: 118. doi: http://dx.doi. org/10.15344/2393-8498/2015/118

Copyright: () 2015 Jeong. This is an open-access article distributed under the terms of the Creative Commons Attribution License, which permits unrestricted use, distribution, and reproduction in any medium, provided the original author and source are credited. 